\title{
Anesthetic management of a patient with limb-girdle muscular dystrophy 2B:CARE- compliant case report and literature review
}

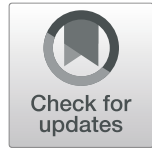

\author{
X. Q. Cao ${ }^{1}$, K. Joypaul ${ }^{2}$, F. Cao ${ }^{3}$, L. L. Guil ${ }^{1}$, J. T. $\mathrm{Hu}^{4}$ and W. Mei ${ }^{1 *}$ (D)
}

\begin{abstract}
Background: Limb-girdle muscular dystrophies (LGMDs) belong to few neuromuscular disorders mainly involving pelvic and shoulder girdle muscles. Also, cardiac or pulmonary complications, increased rhabdomyolysis risk when exposed to volatile anesthetics and succinylcholine may increase anesthesia related risks. However, current reports about the anesthesia management of these patients are limited.
\end{abstract}

Case presentation: We described our anesthetic management of a 36 years old woman with LGMD $2 B$ receiving arthroscopic knee surgery. In consideration of the high risk of rhabdomyolysis, total intravenous anesthesia (TIVA) was selected for her surgery. Considering the unpredictable respiratory depression, opioid based patient-controlled intravenous analgesia was replaced with an intra-articular cocktail therapy consisting of $20 \mathrm{ml} \mathrm{of} 0.2 \%$ ropivacaine. Also, we reviewed the literatures on anesthetic management of LGMD through searching PubMed, in order to provide a comprehensive and safe guidance for the surgery.

Conclusions: Carefully conducted general anesthesia with TIVA technique is a good choice for LGMD patients. Neuraxial anesthesia may be used if general anesthesia needs to be avoided. To warrant safe anesthesia for surgery, any decision must be well thought out during perioperative period.

Keywords: Limb-girdle muscular dystrophy 2B, Anesthesia, Surgery

\section{Background}

Limb-girdle muscular dystrophies (LGMDs) belong to few very rare neuromuscular disorders mainly involving pelvic and shoulder girdle muscles [1]. The estimated incidence of this disease is 1 to 6.5 in 100,000 [2]. Although named as the typical muscle, LGMDs are actually a group of systemic diseases and may be complicated with cardiac or pulmonary involvements [3]. Increased risk of rhabdomyolysis and malignant hyperthermia $(\mathrm{MH})$ when exposed to volatile anesthetics and succinylcholine are life-threatening complications [1]. However, the current reports about anesthetic management of LGMD patients are limited. We aimed to present our clinic experience about a patient with LGMD $2 \mathrm{~B}$ receiving arthroscopic knee surgery. Then, we reviewed literatures on anesthetic management of LGMD published

\footnotetext{
* Correspondence: wmei@hust.edu.cn

${ }^{1}$ Department of Anesthesiology and Pain Medicine, Tongji Hospital, Tongji Medical College, Huazhong University of Science and Technology, 1095 Jiefang Road, Wuhan 430030, People's Republic of China

Full list of author information is available at the end of the article
}

in PubMed, in order to provide a comprehensive and safe guidance for surgery. The reporting of this case was approved by the Research and Ethics Committee of Tongji Hospital at Tongji Medical College, Huazhong University of Science and Technology (TJ-IRB20180902). The patient had gave written informed consent for reporting and publishing her clinical data and images.

\section{Case presentation}

A 36 years old woman, $54 \mathrm{~kg}$ in weight, $1.60 \mathrm{~m}$ tall, BMI 21.09, was hospitalized with left knee joint injury and was scheduled for arthroscopy of left knee (Fig. 1). She had a history of LGMD type 2B diagnosed in 2013 by muscle biopsy. Genetic testing showed homozygous DYSF mutation on 11 and 33 exons, and MRI revealed fat infiltration and fluid collection within the lower limb muscles. Her symptoms predominantly affected her lower limbs. Her initial symptom presented as difficulty in climbing stairs at 24 years old. During her admission, she did not have any muscle weakness in the upper 


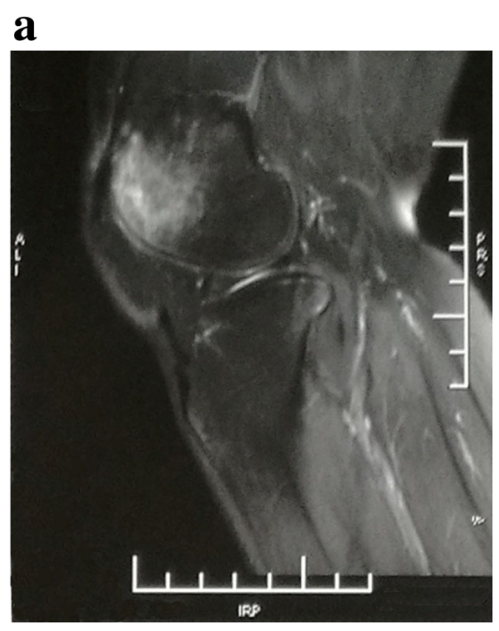

\section{b}
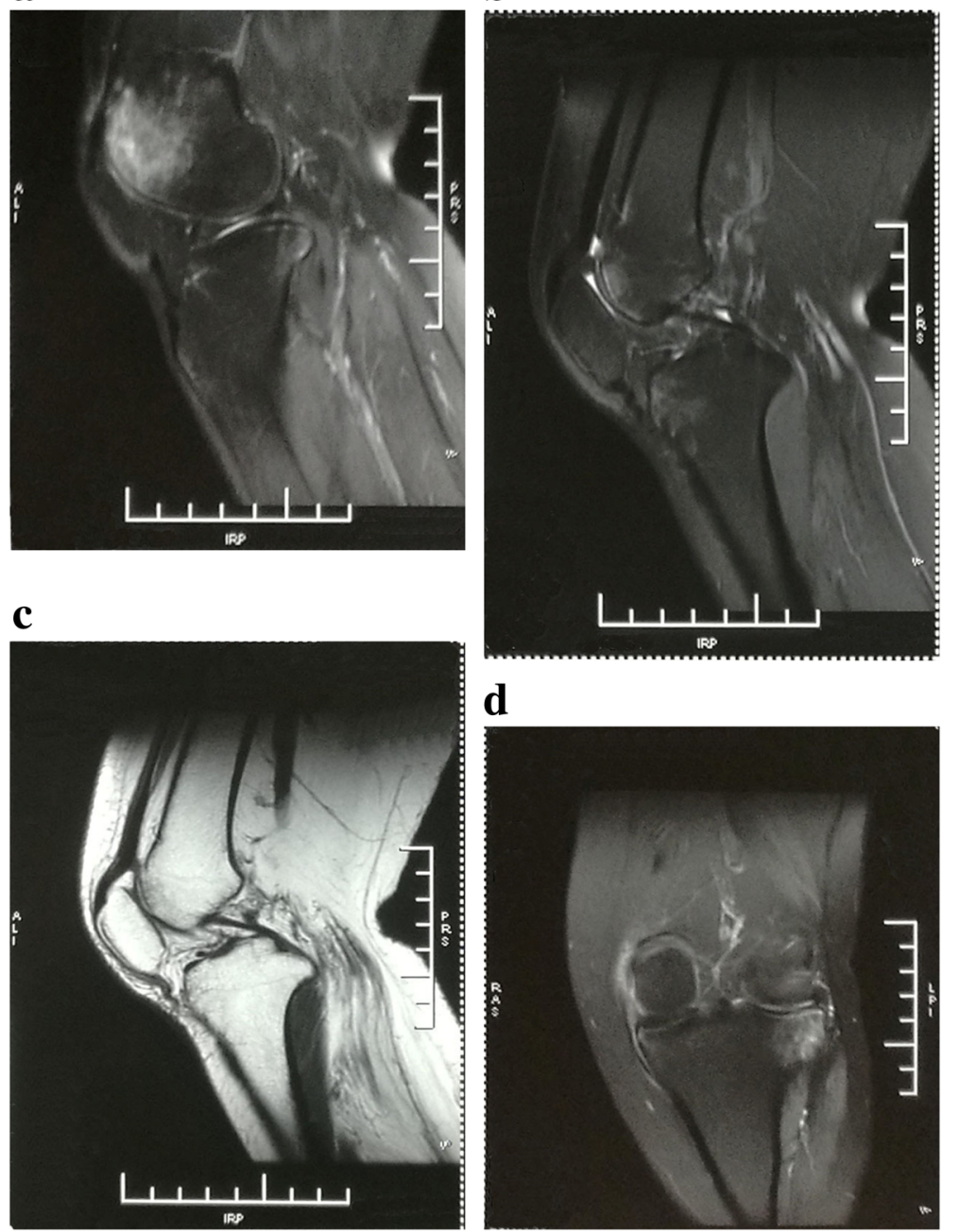

d

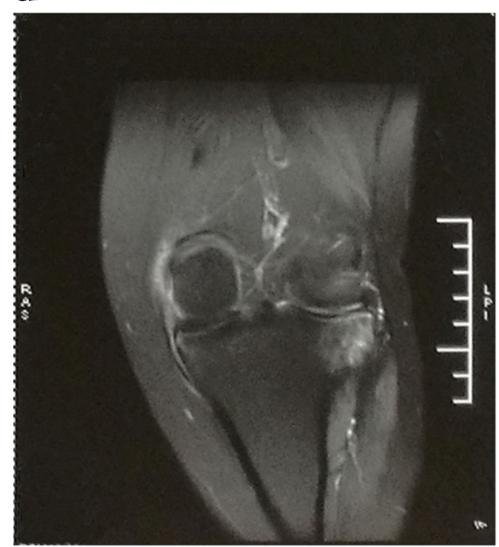

Fig. 1 Left knee joint magnetic resonance imaging. It revealed left knee joint injury. a Osteoedema of distal femur; b Rupture of anterior cruciate ligament; c Relaxation of quadriceps femoris tendon and patellar ligament; $\mathbf{d}$ Posterolateral osteoedema of tibial plateau

limbs, dysphagia, or other clinical manifestations. Her symptoms were slow in progression, with inability to climb the stairs by 2011. She underwent multiple examinations for muscle enzyme levels, electromyography (EMG), etc., and she was also once misdiagnosed as 'polymyositis'. Aspartate aminotransferase (AST), alanine aminotransferase (ALT) and creatine kinase (CK) levels were high. She underwent an uneventful cesarean section under spinal anesthesia in February of 2017. Her younger brother was also diagnosed with LGMD type 2B.

Her current physical examination was remarkable, muscle strength, muscle tension, and muscular volume of the upper limbs were all found to be normal. Muscle strength of the lower limbs was at level 4, whereas muscle tension was decreased (Fig. 2). MRI of lower limbs revealed atrophy of quadriceps femoris, adductor muscles, semimembranosus, and hypertrophy of gracilis as well as the long head of biceps femoris. Her complete blood count, blood chemistry and urinalysis were unremarkable. Abnormal laboratory findings were listed as follows: aspartate aminotransferase $83 \mathrm{U} / \mathrm{L}$, alanine transaminase $43 \mathrm{U} / \mathrm{L}$ and creatine kinase $3479 \mathrm{U} / \mathrm{L}$. The electrocardiogram (ECG) showed $\mathrm{T}$ wave anomaly in the anterior wall. Chest X-ray revealed increased lung markings. After entering the operating room, the patient underwent transthoracic echocardiography and revealed good left ventricular functions and no evidence of cardiomyopathy or pulmonary hypertension.

The patient received adequate explanation about the increased risk of anesthesia and gave her informed consent. In consideration of the high risk of rhabdomyolysis and malignant hyperthermia, we decided to proceed with total intravenous anesthesia (TIVA) for her elective surgery. 


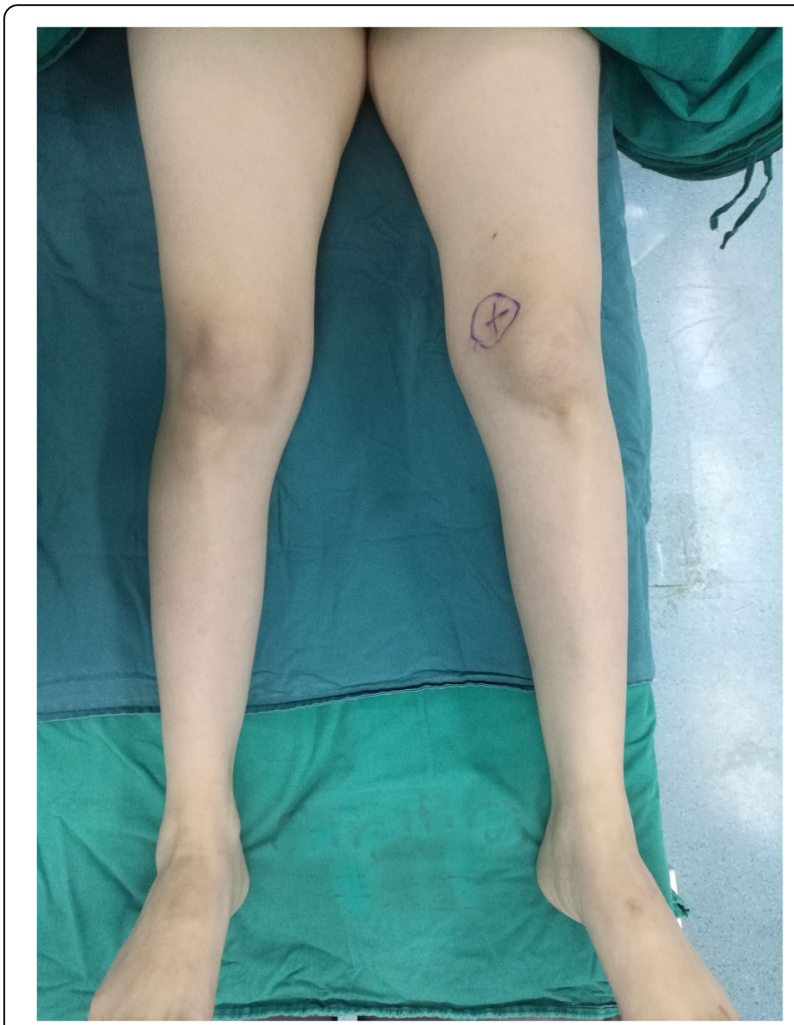

Fig. 2 photograph of patient's lower limbs. It showed muscles of lower limbs atrophy slightly. Muscle strength of the lower limbs was at level 4, whereas muscle tension was decreased
Before the patient was transferred to operating room, the anesthesia apparatus was substituted by a respirator connected with a new breath circuit for necessary isolation from volatile anesthetics. After the patient arrived in the operation room, electrocardiogram and pulse oximetry saturation $\left(\mathrm{SpO}_{2}\right)$ monitoring was immediately started. Heart rate was $74 \mathrm{bpm}$, $\mathrm{SpO}_{2}$ was $98 \%$ in room air. Noninvasive blood pressure (NIBP) was $113 / 62 \mathrm{mmHg}$. To avoid the potential muscular damage caused by repeated cuff pressure measurements, invasive blood pressure monitoring was used. Except for the standard monitoring, end-tidal $\mathrm{CO}_{2}\left(\mathrm{EtCO}_{2}\right)$ and nasopharyngeal temperature monitoring were also important. Flurbiprofen $50 \mathrm{mg}$ was given intravenously as preventive analgesia regime. Anesthesia induction was performed with $50 \mathrm{mg}$ propofol and $20 \mathrm{mg}$ etomidate after $30 \mu \mathrm{g}$ sufentanil, a size 3\# laryngeal mask airway was inserted $2 \mathrm{~min}$ later to secure the airway. Muscle relaxant was not used to avoid the delayed recovery of muscular strength. Propofol $\left(6-12 \mathrm{mg} \cdot \mathrm{kg}^{-1} \cdot \mathrm{h}^{-1}\right)$ and remifentanil $\left(0.1-0.2 \mu \mathrm{g} \cdot \mathrm{kg}^{-1} \cdot \mathrm{min}^{-1}\right)$ were pumped to maintain anesthesia. Non-tourniquet technology was adopted during the operation to avoid potential muscle damage caused by tourniquet, and controlled hypotension was used to reduce the risk of bleeding. During the operation, heart beat was between 55 and $82 \mathrm{bpm}$, while the mean blood pressure remained between 70 and $83 \mathrm{mmHg}$. EtCO $\mathrm{tC}_{2}$ was maintained at around $40 \mathrm{mmHg}$. Nasopharyngeal temperature was monitored at $36.2-36.4^{\circ} \mathrm{C}$. After the surgical intervention which lasted around $1 \mathrm{~h}$ and $48 \mathrm{~min}$, the patient recovered rapidly approximately within $2 \mathrm{~min}$ after cessation of TIVA. Considering the unpredictable respiratory depression, opioid based patient-controlled intravenous analgesia was not used. Instead an intraarticular cocktail therapy consisting of $20 \mathrm{ml}$ of $0.2 \%$ ropivacaine was injected at the end of surgery acting as a substitute for postoperative analgesia.

During the follow-up on the second postoperative day, the resting visual analog scale (VAS) pain score was 2 and the VAS pain score at movement was 4 . The patient could be mobilized out-of-bed, didn't complain of any significant discomfort during movement of the lower limbs. She was discharged on the fifth day after surgery.

Then, we reviewed relevant literatures published in PubMed as of September 2018. The search was limited to studies about humanity. Only English cases were included. The keywords used for the search included ["limb-girdle muscular dystrophy" OR "limb-girdle muscular dystrophy" OR "LGMD"] and ["anesthetic management" OR "anesthesia" OR "anaesthetic management" OR "anaesthesia"].

\section{Discussion and conclusion}

LGMD constitutes a group of genetic disorders originally devided into autosomal dominant (LGMD type 1) and autosomal recessive (LGMD type 2) [4-6], 8 subtypes of LGMD1 and 26 subtypes of LGMD2 are currently recognized [3]. Successive letters of the alphabet have been used to name the LGMDs according to the identification chronology of genetic locus. The pathogenesis of LGMD is the mutation of causative genes leading to abnormal protein synthesis localized to various parts of the muscle fiber [2]. Degeneration and necrosis of muscle fibers, which are replaced by connective tissue and fat is the classic pathologic change [7]. However, the biopsy findings among the various LGMDs lack in specificity and significant overlap. Also, Serum creatine kinase (CK) levels couldn't reflect the severity of LGMD [3]. Genetic testing is necessary for diagnosis of LGMD.

The mutations of dysferlin gene (DYSF, MIM*603009) located on chromosome 2p13.3 induces abnormal dysferlin protein synthesis is the reason of LGMD 2B [8]. The symptom onset ranges from adolescence to late adulthood (17-30 years of age), the disease progresses fairly slowly, and approximately $10 \%$ of patients may be confined to a wheelchair [9]. 
Serum CK levels are considerably high, usually up to 40 times of the normal $[10,11]$.

The use of inhalation anesthetics and succinylcholine may lead to threatening hyperkalemia and rhabdomyolysis, and should be avoided [12-14]. Propofol, etomidate and opioids are proved to be trigger-free agents $[15,16]$. However, myopathic patients are more sensitive to anesthetics, opioids and muscle relaxants [17]. In order to minimize the risk of postoperative respiratory depression, short acing anesthetic agents are the optimum selection [14]. Propofol, as it's short-acting, easiness in titration, is suitable for LGMD [1]. Remifentanil was also unlikely to cause postoperative respiratory failure and prolonged sedation. Therefore, we chose total intravenous anesthesia (TIVA) by infusing propofol and remifentanil for anesthetic maintenance of this patient. Sufentanil $30 \mu \mathrm{g}$ was also used in this patient to provide adequate analgesia. Considering the high sensitivity and prolonged duration of action to muscle relaxants in these patients, muscle relaxants were avoided in our case. Therefore, for this patient laryngeal mask airway is more beneficial as compared to an endotracheal intubation. Intravenous patient-controlled analgesia (iv-PCA) based on opioids may lead to unpredictable respiratory depression, and was not considered in our case. Instead, intra-articular injection of cocktail therapy with $0.2 \%$ ropivacaine $20 \mathrm{ml}$ had been used with an excellent outcome.

Previous reports were searched through PubMed as of September 2018 using the following key words: ["limbgirdle muscular dystrophy" OR "limb girdle muscular dystrophy" OR "LGMD"] and ["anesthetic management" OR "anesthesia" OR "anaesthetic management" OR "anaesthesia"]. Only English reports were included. Six cases were reviewed. Time of publication, LGMD type, symptoms, complications, operative procedures, preoperative examinations, intraoperative monitoring, anesthesia method, anesthesia machine preparation, anesthesia induction, anesthesia maintenance, pain management after operation are summarized in Table 1.

Through literature review, we found that respiratory impairment was common in LGMD [10], and thus the high risk of respiratory compromise should be considered when we administer any anesthesia to a patient with LGMD. Additionally, cardiac impairment should be noticed as well [10]. ECG and Chest X-ray should be performed routinely before surgery, and then for any positive finding, echocardiography and pulmonary function test are suggested. In six previous case reports, two patients underwent laparoscopic cholecystectomy, one patient had appendectomy, one patient underwent caesarean section, one patient had an adenoidectomy, and the last patient went through replacement of ascending aorta. Four operations were performed under TIVA, and the other two operations were performed under neuraxial anesthesia including one laparoscopic cholecystectomy and one caesarean section. Propofol and remifentanil were also adopted as primary anesthetics. If muscle relaxants must be used during operation, neuromuscular blockade monitoring was routinely recommended and sugammadex was used to reverse the blockade at the end of the operation. Among previous case reports, no patient received patient-controlled opioid infusion pumps for postoperative analgesia, and no patient experienced respiratory depression. Our anesthetic strategy was basically in parallel with the regime used in these reports. However, we should keep in mind that the use of TIVA couldn't completely avoid the risk of $\mathrm{MH}$ [22]. Therefore, regional anesthetic techniques should be considered as an alternative plan. Gerbershagen $\mathrm{MU}$ et al. suggested regional anesthetic techniques should be chosen whenever possible in myopathic patients [14, 23]. When using regional anesthesia for patients with LGMD, the myotoxic effects of local anesthetic is unfortunately a primary concern. Wolfgang Zink et al. found that continuously infusing bupivacaine and ropivacaine for femoral nerve block could induce acute muscle damage with similar histological patterns [24]. They also found that both agents induced ineversible skeletal muscle damage [25], and the complex pathophysiology of local anesthetic myotoxicity had also been reviewed correspondingly [26]. This phenomenon was also demonstrated by other studies [27-29]. Though many of these studies were experimental in animals, and almost all these studies showed some local muscle damages after continuous peripheral nerve blocks, there were also some case reports in clinic about mytoxicity of local anesthetic [30-32]. In this respect, it might be necessary for a LGMD patient to avoid continuous peripheral nerve block with higher concentration of local anesthetics. In contrast, both epidural and combined spinal-epidural anesthesia have been safely used for LGMD patients receiving cesarean section $[1,20]$. So far there was no study about myotoxicity after neuraxial anesthesia. It's preferred to use neuraxial anesthesia in LGMD patients whenever general anesthesia had to be avoided or carried an increased risk of complication.

In summary, carefully conducted general anesthesia with TIVA technique is a good choice for LGMD patients. Neuraxial anesthesia may be used if general anesthesia needs to be avoided. To warrant safe anesthesia for surgery in LGMD patients, a comprehensive preoperative evaluation, advanced intraoperative monitoring, thoughtful choice of anesthetic technique and pain management strategy, as well as with cooperation of a multidisciplinary team including pulmonologist, critical care physicians, and neuromuscular disease specialists is mandatory. 


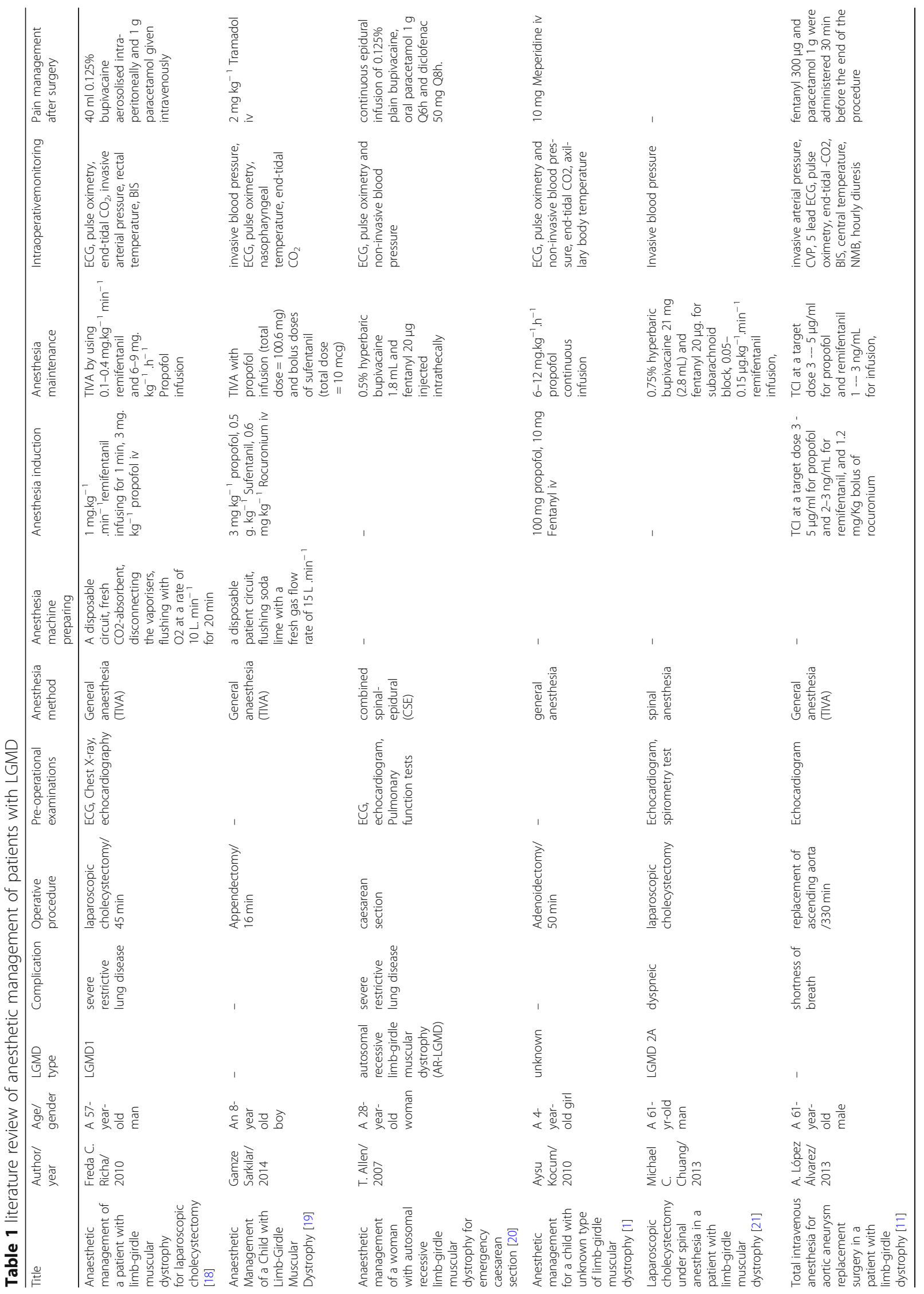




\section{Abbreviations}

$\mathrm{EtCO}_{2}$ : End-tidal $\mathrm{CO}_{2}$; Iv-PCA: Intravenous patient-controlled analgesia; LGMD: Limb-girdle muscular dystrophy; MH: Malignant hyperthermia; TIVA: Total intravenous anesthesia; VAS: Visual analog scale

\section{Acknowledgements}

Not applicable.

\section{Authors' contributions}

Concept- MW; Design- MW, CXQ; Supervision-MW; Materials- CXQ, HJT; Data Collection and Processing - CXQ; Analysis and /or Interpretation -MW, CXQ; Literature Review- MW, CXQ; Draft- CXQ; Critical Review- MW, K. J, CF, GLL. All authors gave their comments on the article and approved the final version.

\section{Funding}

The authors declared that this case has received no financial support.

\section{Availability of data and materials}

The data used or presented during this study are available from the corresponding author on request.

\section{Ethics approval and consent to participate}

This case report was approved by the Research and Ethics Committee of Tongji Hospital, Tongji Medical College, Huazhong University of Science and Technology. The reference number for the ethics approval is: TJ-IRB20180902.

\section{Consent for publication}

The consent for publication of this case report and any accompanying images was obtained from this patient. Written informed consent had been got.

\section{Competing interests}

The authors declare that they have no competing interests.

\section{Author details}

'Department of Anesthesiology and Pain Medicine, Tongji Hospital, Tongji Medical College, Huazhong University of Science and Technology, 1095 Jiefang Road, Wuhan 430030, People's Republic of China. ${ }^{2}$ Department of Anesthesiology, Flacq Hospital, Hospital Road, Centre-de-Flacq, Mauritius. ${ }^{3}$ Department of Psychiatry, University of Missouri-Kansas City, 5100 Rockhill Road, Kansas City 64110, MO, USA. ${ }^{4}$ Department of Anesthesiology, Wuhan No.4 Hospital, 473 Hanzheng Road, Wuhan 430033, People's Republic of China.

Received: 21 March 2019 Accepted: 29 July 2019

Published online: 17 August 2019

\section{References}

1. Kocum A, Sener M, Caliskan E, Aribogan A. Anesthetic management for a child with unknown type of limb-girdle muscular dystrophy. Pediatr Int. 2010;52(1):e37-8

2. Iyadurai SJ, Kissel JT. The Limb-Girdle Muscular Dystrophies and the Dystrophinopathies. Continuum (Minneap Minn). 2016;22(6, Muscle and Neuromuscular Junction Disorders):1954-77.

3. Chu ML, Moran E. The limb-girdle muscular dystrophies: is treatment on the horizon? Neurotherapeutics. 2018;15:849-62

4. Patel NJ, Van Dyke KW, Espinoza LR. Limb-girdle muscular dystrophy $2 \mathrm{~B}$ and Miyoshi presentations of Dysferlinopathy. Am J Med Sci. 2017;353(5):484-91.

5. Bushby KM, Beckmann JS. The limb-girdle muscular dystrophies--proposal for a new nomenclature. Neuromuscul Disord. 1995;5(4):337-43.

6. Joyce NC, Oskarsson B, Jin LW. Muscle biopsy evaluation in neuromuscular disorders. Phys Med Rehabil Clin N Am. 2012;23(3):609-31.

7. Liu J, Aoki M, Illa I, Wu C, Fardeau M, Angelini C, Serrano C, Urtizberea JA, Hentati F, Hamida MB, et al. Dysferlin, a novel skeletal muscle gene, is mutated in Miyoshi myopathy and limb girdle muscular dystrophy. Nat Genet. 1998:20(1):31-6.

8. Oh SH, Kang SW, Lee JG, Na SJ, Kim TS, Choi YC. Clinical and pathological characteristics of four Korean patients with limb-girdle muscular dystrophy type 2B. J Korean Med Sci. 2004;19(3):447-52.

9. Domingos J, Sarkozy A, Scoto M, Muntoni F. Dystrophinopathies and limbgirdle muscular dystrophies. Neuropediatrics. 2017;48(4):262-72.
10. Murphy AP, Straub V. The classification, natural history and treatment of the imb girdle muscular dystrophies. J Neuromuscul Dis. 2015:2(s2):S7-S19.

11. Lopez AA, Roman FA, Vilanova W, Corujeira RM, Arean Gl, Valino HC. Total intravenous anesthesia for aortic aneurysm replacement surgery in a patient with limb-girdle dystrophy. Rev Esp Anestesiol Reanim. 2014;61(7):385-7.

12. Yemen TA, McClain C. Muscular dystrophy, anesthesia and the safety of inhalational agents revisited; again. Paediatr Anaesth. 2006;16(2):105-8.

13. Schieren M, Defosse J, Bohmer A, Wappler F, Gerbershagen MU. Anaesthetic management of patients with myopathies. Eur J Anaesthesiol. 2017;34(10):641-9.

14. Wappler F. Anesthesia for patients with a history of malignant hyperthermia. Curr Opin Anaesthesiol. 2010:23(3):417-22

15. Kim TW, Nemergut ME. Preparation of modern anesthesia workstations for malignant hyperthermia-susceptible patients: a review of past and present practice. Anesthesiology. 2011;114(1):205-12.

16. Muenster T, Forst J, Goerlitz P, Schmitt HJ. Reversal of rocuronium-induced neuromuscular blockade by pyridostigmine in patients with Duchenne muscular dystrophy. Paediatr Anaesth. 2008;18(3):251-5.

17. Shapiro F, Athiraman U, Clendenin DJ, Hoagland M, Sethna NF. Anesthetic management of 877 pediatric patients undergoing muscle biopsy for neuromuscular disorders: a 20-year review. Paediatr Anaesth. 2016;26(7):710-21.

18. Richa F C. Anaesthetic management of a patient with limb-girdle muscular dystrophy for laparoscopic cholecystectomy[]]. Eur J Anaesthesiol. 2011;28(1):72-73.

19. Sarkilar G, Mermer A, Yucekul M, Ceken BM, Altun C, Otelcioglu S. Anaesthetic Management of a Child with Limb-Girdle Muscular Dystrophy. Turk J Anesth Reanim. 2014;42(2):103-105

20. T. Allen, S. Maguire. Anaesthetic management of a woman with autosomal recessive limb-girdle muscular dystrophy for emergency caesarean section. Int J Obstet Anesth. 2007:16(4):370-374

21. Michael C. Chuang, Laura V. Duggan, Rardi D. van Heest, Wendy MacLeod. Laparoscopic cholecystectomy under spinal anesthesia in a patient with imb-girdle muscular dystrophy. Can J Anesth/J canadien d'anesthésie. 2013; 60(12):1276-1277

22. Gerbershagen MU, Wappler F. Anesthesia with neuromuscular diseases. Anaesthesist. 2010;59(10):953-65 966-967.

23. Zink W, Seif C, Bohl JR, Hacke N, Braun PM, Sinner B, Martin E, Fink RH, Graf $\mathrm{BM}$. The acute myotoxic effects of bupivacaine and ropivacaine after continuous peripheral nerve blockades. Anesth Analg. 2003:97(4):1173-9.

24. Zink W, Bohl JR, Hacke N, Sinner B, Martin E, Graf BM. The long term myotoxic effects of bupivacaine and ropivacaine after continuous peripheral nerve blocks. Anesth Analg. 2005;101(2):548-54

25. Zink W, Graf BM. Local anesthetic myotoxicity. Reg Anesth Pain Med. 2004; 29(4):333-40.

26. Otsuki S, Yasuda T, Mukaida K, Noda Y, Kanzaki R, Miyoshi H, Kondo T, Hamada $\mathrm{H}$, Kawamoto M. Myotoxicity of local anesthetics is equivalent in individuals with and without predisposition to malignant hyperthermia. J Anesth. 2018:32(4):616-23.

27. Nouette-Gaulain K, Sirvent P, Canal-Raffin M, Morau D, Malgat M, Molimard M, Mercier J, Lacampagne A, Sztark F, Capdevila X. Effects of intermittent femoral nerve injections of bupivacaine, levobupivacaine, and ropivacaine on mitochondrial energy metabolism and intracellular calcium homeostasis in rat psoas muscle. Anesthesiology. 2007;106(5):1026-34.

28. Nouette-Gaulain K, Bellance N, Prevost B, Passerieux E, Pertuiset C, Galbes O, Smolkova K, Masson F, Miraux S, Delage JP, et al. Erythropoietin protects against local anesthetic myotoxicity during continuous regional analgesia. Anesthesiology. 2009:110(3):648-59.

29. Neal JM, Salinas FV, Choi DS. Local anesthetic-induced myotoxicity after continuous Adductor Canal block. Reg Anesth Pain Med. 2016:41(6):723-7.

30. Capdevila X, Pirat P, Bringuier S, Gaertner E, Singelyn F, Bernard N, Choquet $\mathrm{O}$, Bouaziz H, Bonnet F. Continuous peripheral nerve blocks in hospital wards after orthopedic surgery: a multicenter prospective analysis of the quality of postoperative analgesia and complications in 1,416 patients. Anesthesiology. 2005;103(5):1035-45.

31. Mather C, McSwiney M. Anaesthesia-related diplopia after cataract surgery. Br J Anaesth. 2003:91(1):152, 152-3.

32. Ranjan RV, Ramachandran TR, Manikandan S, John R. Limb-girdle muscular dystrophy with obesity for elective cesarean section: anesthetic management and brief review of the literature. Anesth Essays Res. 2015;9(1):127-9.

\section{Publisher's Note}

Springer Nature remains neutral with regard to jurisdictional claims in published maps and institutional affiliations. 